\title{
Authentic learning and the research processes of gifted students
}

\section{Bishop, Kay}

International Association of School Librarianship. Selected Papers from the ... Annual Conference; 1999;

Education Database

pg. 51

\section{Authentic Learning and the Research Processes of Gifted Students}

\author{
Kay Bishop, Ph.D \\ <kbish0@pop.uky.edu> \\ Associate Professor \\ University of South Florida \\ United States of America
}

\begin{abstract}
This study utilizes qualitative research methods (observations, interviews, and analysis of written documents) to investigate the research processes of ten gifted students who participated in independent research projects. Research stages dealing with exploring and forming a focus presented the most difficulty for the students. The three students who were able to establish a clear focus were the only ones who demonstrated all aspects of authentic learning. An additional research question deals with the types of resources used by the students. Books and videocassettes were the primary sources used by the students. All students were highly dependent on the teacher as a source of information. The researcher points out the absence of collaboration between the teacher, the school librarian, and the public librarian. The researcher also calls for the examination of cooperative learning, intervention, required assignment deadlines, and the format of products as each of these relate to independent research projects.
\end{abstract}

\section{Introduction}

Teachers frequently give gifted the opportunity to participate in independent research projects, reasoning that such assignments allow the students to explore their own interests, produce creative products, and engage in meaningful learning experiences. But how important is understanding the research process itself and being able to access and utilize a variety of sources to such an assignment? Are the independent research projects fulfilling the intended goals for all gifted students? How might the process be altered to make such an assignment produce more authentic learning experiences for each gifted student? This case study of ten ninth grade students in a junior high class for gifted students investigates these questions. $^{1}$

This study extends and applies the information obtained from previous studies that have dealt with (a) the research processes of young people, (b) the types of information sources used by gifted students, and (c) the application of authentic assessment standards to learning.

Previous studies related to these topics include a research model developed and tested by Kuhlthau $(1985,1988,1989,1990,1993)$, a study by Burdick $(1996,1997)$ that used Kuhlthau's model and emphasized the focus formulation stage of the model, studies by McGregor (1994) and Pitts (1994, 1995) that provided insights into the research processes of young people, and Reis and Renzulli's (1992) research describing a twelve-step methodology 
that teachers or media specialists can use to guide high ability students in independent research projects.

Latrobe and Havener (1997) explored the types of information consulted by high school honor students, and Newmann, Secada, and Wehlage (1995) wrote a monograph in which they defined authentic learning by using three criteria: construction of knowledge, disciplined inquiry, and value beyond school.

\section{Research Questions}

A case study using qualitative research methods was selected as the most appropriate means of obtaining data to investigate the following research questions that served as guides to the study: (1) What are the processes, thoughts, and feelings that gifted students experience while participating in an independent research project? (2) From what sources do gifted students obtain their information for an independent research project? (3) Do independent research projects produce authentic learning for gifted students?

\section{Methodology}

Purposive sampling was used to select a school district where there was a well-established gifted program for students. The selected classroom was in a junior high school in a southeastern state. At the request of the school district, the school remains anonymous in the study and fictitious names have been used for the teacher and the students. The teacher had several years of experience as a teacher of gifted students. The school was located in a primarily middle class neighborhood, with a variety of racial backgrounds represented in the student body. The ninth grade classroom chosen for the study consisted of ten students-six girls and four boys, nine Caucasians and one African-American. All the students were formally identified as gifted using a combination of criteria that included formal testing. The students were in the gifted classroom during one period of the day.

During the three days prior to the beginning of the independent research project the researcher observed the students while they participated in panel discussions relating to a NASA project in which they had been involved. Most of the students were friendly and outgoing. They chatted informally with the researcher, and none of the students seemed uncomfortable with the presence of the researcher in the classroom. Thus, the researcher assumed the role of "participant observer," the term used to describe the researcher who enters the world of the people he or she plans to study (Bogdan \& Biklen, 1982).

The researcher spent twelve weeks during the spring semester gathering data related to the students' independent research projects. Data gathering methods included the following: (1) observations, during which field notes were recorded; (2) informal interviews with the students, the teacher, a public librarian, and the school librarian; and (3) analysis of documents including papers distributed by the teacher, information sources gathered by the students, and the final student research products. Qualitative researchers recommend the use of multiple data sources and research techniques (Pyke \& Agnew, 1991). This method of 
"triangulating" data sources minimizes bias and maximizes the amount and quality of data gathered (Westbrook, 1989).

Field notes from observations and interviews, as well as notes taken from the analysis of documents, were coded and analyzed. The researcher looked for patterns and trends that provided the findings for the study.

\section{Results/Findings}

\section{The Research Process}

Receiving the Assignment. Before beginning the independent research project the instructor, Mr. Roberts, spent one class period discussing the assignment. He provided the students with handouts and talked to them about note-taking. There were no specific deadlines for the independent research project, but he did mention that the class would spend about nine weeks on it.

Selecting a Topic. Students were allowed to select their own topics for independent research. Before walking with the students to a nearby public library Mr. Roberts discussed project ideas with the students. Two of the nine students, Mary Ann and Scott, had fairly definite ideas of the topics they planned to research. One of the students had many ideas, four had a few ideas, and three had no ideas. The amount of time for topic selection varied greatly, from the first day the students discussed topics to twelve days later. Elaine waited until the twelfth day and selected a topic (Janis Joplin) only after Mr. Roberts checked out some books from the public library and placed them in her research carrel. Elaine did state, however, that she was glad to finally have a topic. This was the first sign of enthusiasm or optimism expressed by her since the beginning of the assignment. Elaine's response coincided with Kuhlthau's model in which students have feelings of optimism when a topic is selected. All the students expressed a sense of optimism as they selected their topics, although again there was great variation in their level of optimism.

Exploring for a Focus. Kuhlthau's third stage in the research model is exploring for a focus. In her model feelings of confusion, frustration, and doubt accompany this stage. Kuhlthau reports that half of the students in her studies was successful obtaining a clear focus for their research, while the other half of the students was not. Burdick's (1997) findings were similar, but in her study she went on to delineate three types of students in regard to the focus of their projects: Navigators (students who were highly focused), Tourists (students who narrowed their topics somewhat), and the Lost and Wanderers (students who were only able to express a vague description of their topics).

The researcher classified four of the students-Michael, Lara, J.C., and Elaine-as Lost and Wanderers. Although they did collect some materials and go on to make presentations, they never seemed to have a clear focus. When questioned by the researcher at various times about their projects, they were unable to verbalize what questions they had about their topics or what they were trying to discover.

The researcher placed three of the students in the Tourist category: Linda and Jana (who worked collaboratively on the topic of magic) and Steven (who investigated nonverbal 
expression using a clay model). They somewhat narrowed their topics and explored them by collecting information.

Three students, Jennifer, Scott, and Mary Ann, achieved the attributes of Burdick's Navigators. Each of these students formulated a clear focus, and each followed the cognitive and affective stages of Kuhlthau's model. As mentioned earlier, Scott (robotics) and Mary Ann (polymer science) selected their topics almost immediately. Mary Ann was unable to find the sources she needed, but clearly focused on the topic of bubbles when she switched topics. Scott, although using a fairly small number of information sources in the collection stage, kept a clear focus throughout his research. Jennifer, who investigated autism, was perhaps the most "classic case" of Kuhlthau's entire research process in this study.

Forming a Focus. Jennifer provided an interesting case study during this fourth stage, which Kuhlthau calls "forming a focus," and the following stage, "collecting information." After trying to suggest the topic of autism to Elaine, she decided to explore it herself. Up to that point she had been thinking in the broader areas of sign language or child prodigies. She told the researcher she was trying to figure out a way of tying sign language to autism. She became clearly focused on the topic and had a number of questions she wanted to investigate.

Collecting Information. Jennifer stayed focused on her topic during the remainder of the research process. She immediately began gathering sources from a variety of places. She contacted people who knew about autism, checked out books and videos from the public library (and put others on reserve), and borrowed videos from video rental stores in town. She clearly displayed a sense of direction and much confidence throughout this stage.

Preparing to Present. In this stage Kuhlthau describes the students as feeling either a sense of satisfaction or dissatisfaction. The feelings of satisfaction were apparent in the students who were focused (the Navigators) during the research process. Mary Ann, Jennifer, and Scott were all excited about their presentations and talked with the researcher about what they planned to do. All of their presentations were well organized and displayed much creativity.

The other students lagged noticeably behind in their preparations to present. Jana, Linda, and Stephen (the Tourists) presented during the eleventh week of research. Their presentations exhibited information they had obtained but lacked the organization and focus of the three previous presentations.

Elaine (categorized as a Lost or Wanderer) was the next to present. As mentioned earlier, Elaine showed little interest in the research process, and she received much assistance in her preparations for her presentation. When she decided to make a video for a product ("because Mr. Roberts suggested it and Steven is making a video so I guess I will"), she was very dependent on Mr. Roberts and Jennifer to help her complete her video. However, once she got into her topic presentation and began to relax, she surprised Mr. Roberts, the researcher, and the other students with the amount of information she had gathered and how much she had learned about Janis Joplin's life.

Assessing the Product and Process. Although Kuhlthau's original model did not include a stage for assessing the process, she did include it as one of her stages in her book, Teaching the Library Research Process (1994). This step is important enough to merit inclusion in the current study. 
Mr. Roberts continually stressed self-assessment throughout the research process. Early in the research process he talked about evaluation: "How the product performs is your evaluation. Does it support your hypothesis? It doesn't mean if the hypothesis doesn't prove out, you haven't learned."

During the sixth week he called the students together and had them fill out a form, "Almost There: Putting the Finish on an Independent Study Project," that both assessed their progress and guided them to look at the things they needed to accomplish before their presentation. The students then shared their responses orally. Mr. Roberts and the other students offered suggestions for each project. When all the students' presentations were completed, Mr. Roberts and the students evaluated both the research process and their own products.

Mr. Roberts also orally shared with the students his assessment of how he had structured the independent research project: "I think it would have been helpful if I had set some deadlines. Maybe we should have sat down as a class and agreed on some deadlines." He also thought he should have required the students to do more writing, even though the final product was an oral presentation: the writing would have supported the oral presentation. Jennifer's product was the only one in the class that included an accompanying written paper.

Mr. Roberts talked to the researcher after class on one occasion and noted the independent research projects had decreased in quality through the years. He wondered if it had something to do with reading as he said many of his gifted students did not seem to be readers. The projects in the earlier years were set up on a more formal basis, with research questions stated and "discoveries" presented in well-organized, written papers.

\section{Sources of Information}

The second research question for the current study concerns the sources of information used by the students for their independent research projects. The most extensively used sources of information for all the students were books. Most of the students obtained their books from the nearby public library; however, several of the students also brought books from home.

All students appeared to know how to access the online catalog in the public library. One of the students told the researcher that Mr. Roberts had taken the students to the library when it first opened and showed them how to search the catalog. However, similar to the students in Pitts' (1995) study, if these students did not find a source in the catalog they assumed the library had no information on the topic. Although other electronic sources, such as magazine indexes, were available on CD-ROM in the public and school library, the researcher observed only one instance of their use-Jana ran a printout of Houdini from an electronic encyclopedia at the public library. Some students read magazine articles about their topics, but these were primarily provided by Mr. Roberts, who seemed to have large amounts of information in his school files (although much of the information was quite old). On several occasions Mr. Roberts retrieved articles and presented them to the students.

The second most used sources of information were videos. They came from a variety of places - the public library, home, video rental stores, Mr. Roberts' collection, and in one case the school library. The students particularly enjoyed watching the videos and frequently spent entire class periods viewing them. The unfocused students, particularly Lara and J.C., 
spent time viewing other students' videos instead of working on their own projects. Most students took no notes during the videos.

Two students used audiocassettes were used to obtain information. Lara used a cassette of an Irish folktale, and Elaine used a Janis Joplin cassette. In neither case did the student locate the audiocassette on her own.

In Latrobe and Havener's (1997) study of information-seeking behavior, the ninth grade honor students relied heavily on other people for information, and $100 \%$ of those students reported consulting with their teachers. This was also true in the current study where every student in the class relied on Mr. Roberts to provide them with information on their topics. He was remarkably well-rounded in his interests and was able to verbally contribute in-depth information on every student's topic. Additionally, he provided several of the students with materials on their topics or for creation of their products.

Jennifer was the only student who obviously consulted with other adults besides Mr. Roberts for her information needs. Some other students, however, did mention their parents helped them obtain materials for products that they built.

Both the students and Mr. Roberts consulted the librarians at the public library and the school library only for the location of materials. The researcher informally interviewed the reference librarian on duty at the public library and the school media specialist. Both were knowledgeable professionals who were well acquainted with a variety of information sources, possessed the ability to conduct reference interviews, and knew how to integrate information skills into the research process. Both were pleasant individuals who were willing to help the students. However, neither librarian was asked to assist the students in any way except to locate a book on the shelf, put a book on reserve, or provide a blank videotape.

Neither the school library nor the public library had Internet access at the time of the study. Thus the students did not access Internet resources except Jennifer who reported using e-mail on her home computer to obtain some information from individuals about autism.

The use of the school library seemed to be an omission in the research process. When questioned about the school library, Lara responded, "I don't check out books from the school library. Mr. Roberts takes us, but not for research projects. Maybe for something else. He usually brings us here (public library)."

J.C. noted that the public library had more materials than the school, but the university library had the most. He explained he had access to the university library since his mother worked there but many of the students in the class could not check out books from the university library.

When Mr. Roberts was asked about the resources in the school library, he responded that the school library was limited for the depth of research that the gifted students conducted.

The researcher found the school library to be a busy place, with an average number of books for the size of the school. Most of the gifted students in Mr. Roberts' class could have found at least some materials on their topic, except perhaps for Mary Ann's first topic of polymer science. The school librarian stated she did provide resources for Mr. Roberts and his students if they came in during their independent research projects. "If I know his students 
are working on a certain unit, then I'll direct him (Mr. Roberts) and I'll gather resources for him." she explained. Then she added, "He pretty much follows his own curriculum."

\section{Authentic Learning}

Three students (Mary Ann, Jennifer, and Scott) demonstrated authentic learning. All built their research on a prior knowledge base, gained in-depth understandings of their topics, and communicated their learning through complex narratives, rather than simple, brief responses. When asked questions at the end of their presentations, they were able to give involved explanations and all three students talked of additional questions or understandings they had formulated in the research process. They were able to communicate how their research could help them beyond the value of getting a grade for the class. "From reading and building a robot, I got great knowledge of robotics and electronics which can help me with lots of things, like fixing a car," explained Scott.

Aspects of authentic learning, particularly construction of knowledge and the use of a prior knowledge base, could be found in the seven other projects, but none of these projects demonstrated all the aspects of authentic learning as described by Newmann, Secada, and Wehlage (1995). The aspects of authentic learning that were most often absent from the other seven projects were in-depth understanding and the expression of conclusions in complex communication. Most of the seven presentations demonstrated rather simple explanations of what they had learned.

Because Mr. Roberts had directed the students to assess their process and products, all of the students made comments about their research. Some comments were quite insightful and "on target," such as Scott's indication that he thought he should have done more book research, and less hands-on. Steven said, "I wasted two weeks of time. I know I was just bouncing around the room for the first couple weeks." After her presentation, Elaine was more willing to share her thoughts with the researcher, noting, "I guess my presentation went OK-I guess. I guess it could have been better. I could have worked harder. I'm lazy. I admit it." She went on to explain that she had difficulty making decisions and concentrating.

\section{Conclusions and Implications}

Students in the current study experienced the most difficulty with the focus stages (exploring for a focus and forming a focus) of the research process. Kuhlthau (1985, 1988, 1989, 1990, 1993 ) and Burdick $(1996,1997)$ also indicated similar problems and numbers of students having difficulties in the focus stages. Thus, the fact that a student is gifted does not mean he or she will have less difficulty in obtaining a clear focus in an independent research project.

Obviously the focus stages are crucial in the success of the research process. Studies that concentrate on these particular stages of the research process would help educators to better understand how to help students explore and narrow a focus. In the current study the teacher had the students fill out forms to help them establish a focus for their projects. However, there was little or no follow-up with the forms. One-on-one interviews with the students at that point, dealing with both the cognitive and affective aspects of the process, might have helped the students form a clear focus or help them understand why they were experiencing 
difficulties. A teacher might also consider not having a student move on to the next stage (collecting information) until the student verbalizes the research questions and obtains a clear focus

Intervention made a significant impact on the research process in this study. Although the teacher in the current study frequently intervened positively with the students, he did not utilize other adults to assist in the intervention process. School library media specialists, in particular, are trained in the teaching of the research process, the integration of information skills into the research process, and the utilization of information resources. It is important that the teachers of gifted students work collaboratively with the school library media specialists, thus using the expertise and knowledge of these professionals and providing another adult who could make positive interventions. Phone calls made to the parents of the students soliciting their help might also be an additional means of increasing positive intervention in the independent research projects.

The impact of collaboration among students on independent research projects also needs further study. Questions of when, how, and with whom student collaboration positively affects the research process should be investigated. The current study revealed both positive and negative instances of student collaboration. Although educators have joined the rush to get on the "student collaboration bandwagon," this study indicates there is a need to stop, observe, and reflect on examples of student collaboration or cooperative learning. It is important to determine how collaboration best functions so it can be used effectively in the education of gifted students.

Another aspect of educational reform needs some reflection as well. Educators have emphasized producing creative products in research projects, particularly with gifted students. In this study there was little writing produced in those products. It is possible that those students who struggled to find a focus for their projects might have benefited by organizing their thoughts and information in some written form. Teachers of the gifted and school library media specialists need to consider the importance of the written word in research, particularly as they prepare college-bound students who will be asked to produce formal research papers. There should be an appropriate balance in the formats of the student research products.

The teacher in the current study did not want to place pressure on the gifted students by setting up deadlines for selecting topics or moving into the various stages of the research process. Yet, the students who completed the projects first were those who obtained a clear focus in their research and presented the most creative and complete products. Thus, this lack of deadlines to relieve pressure from the research process is an educational opinion that needs careful consideration.

Similar to the females in Burdick's $(1996,1997)$ study (who were not limited to gifted students), four of the six girls in this study exhibited some lack of self-confidence in the independent research process. Even though some boys had similar problems in selecting a topic, finding a focus, or producing an effective presentation, none of them verbalized any lack of confidence. Most said they were satisfied with their efforts. This lack of selfconfidence among the females is a characteristic of the research process that needs further investigation and solutions. 
The most disappointing finding in the current study was that authentic learning was not displayed in all the gifted students' research projects. The three students who were able to find a clear focus and follow through all of Kuhlthau's stages were those who displayed all the criteria of authentic learning. Thus, this study indicates gifted students need to successfully follow through research stages in order to achieve authentic, relevant learning. It cannot be assumed all gifted students will have meaningful learning experiences in an independent research project. It is important that educators reach these underachieving gifted students. These students will continue to need to utilize information for research. As they progress through high school and into college or university, learning how to access and utilize information for research and to successfully move through the research process will significantly improve the chances of obtaining meaningful learning experiences for all gifted students. How best to instruct and guide the students in an independent research project is a serious challenge for all teachers of the gifted and for all school library media specialists.

\section{Notes}

'An article based on this study will appear in the Winter 2000 issue of Gifted Child Quarterly.

\section{References}

Bogdan, Robert C., \& Biklen, Sari (1982). Qualitative research for education. Boston: Allyn and Bacon.

Burdick, Tracey (1996). Success and diversity in information seeking: Gender and the information search styles. School Library Media Quarterly, 25 (1), 19-26.

Burdick, Tracey (1997). Snakes and snails and puppy dog tails: Girls and boys expressing voice in information research projects. Journal of Youth Services in Libraries, 11 (1), 28-36.

Kuhlthau, Carol C. (1985). A process approach to library skills instruction. School Library Media Quarterly, 13 (1) 35-40.

Kuhlthau, Carol C. (1988). Developing a model of the library search process: cognitive and affective aspects. Research Quarterly, 28 (2), 232-242.

Kuhlthau, Carol C. (1989). The information research process of high-middle-low achieving high school seniors. School Library Media Quarterly, 17 (4), 224-228.

Kuhlthau, Carol C., Turock, Betty J., George, Mary W., \& Belvin, Robert J. (1990). Validating a model of the search process: A comparison of academic, public, and school library users. Library and Information Science Research, 12 (1), 5-31. 
Kuhlthau, Carol C. (1993). Seeking meaning: A process approach to library and information services. Norwood, NJ: Ablex.

Kuhlthau, Carol C. (1994). Teaching the library research process. Metuchen, NJ: Scarecrow Press.

Latrobe, Kathy, \& Havener, W. Michael (1997). The information-seeking behavior of high school honors students: An exploratory study. Youth Services in Libraries, 11 (2), 188-200.

McGregor, Joy H. (1994). Cognitive processes and the use of information: A qualitative study of higher-order thinking skills used in the research process by students in a gifted program. In Carol C. Kuhlthau (Ed.), School Library Media Annual 1994, Volume 12 (pp.124-133). Englewood, CO: Libraries Unlimited.

Newmann, Fred M., Secada, Walter G., \& Wehlage, Gary G. (1995). A guide to authentic instruction and assessment: Vision, standards and scoring. Madison, WI: Wisconsin Center for Education Research.

Pitts, Judy M. (1994). Personal understandings and mental models of information: A qualitative study of factors associated with the information seeking and use of adolescents (Doctoral dissertation, Florida State University). Dissertation Abstracts International, 55, 4616.

Pitts, Judy M. (1995). Mental models of information: The 1993-94 AASL/Highsmith Research Award Study School Library Media Quarterly, 23 (4), 177-184.

Pyke, Sandra W., \& Agnew, Neil McK. (1991). The science game: An introduction to research in the social sciences. Englewood Cliffs, NJ: Prentice-Hall.

Reis, Sally M., \& Renzulli, Joseph S. (1992). The library media specialist's role in teaching independent study skills to high ability students. School Library Media Quarterly, 21 (1), 27-35.

Westbrook, D. Lynn (1989). Qualitative evaluation methods for reference services. Washington DC: Office of Management Services, Association of Research Libraries. 